\title{
El café en un área periférica de Costa Rica: Tilarán 1900-1994
}

\author{
Brunilda Hilje Quirós \\ Margarita Torres Hernández ${ }^{1}$
}

\section{Introducción}

De manera generalizada el conocimiento de nuestra historia patria se circunscribe a los textos oficiales, en donde se transmiten datos acerca de hechos y fechas importantes, personajes relevantes, guerras y gastas heroicas, con un determinado enfoque ideológico que ha invisibilizado ciertas regiones y zonas del país, así como a ciertos sectores y personajes. Es por ello que presentamos este artículo con el abordaje del cultivo del café en Tilarán, desde la perspectiva de sus actores, es decir, dándonos la oportunidad de conocer en sus propias palabras cómo vivieron este proceso y cómo lo han conocido e interpretado sus descendientes directos.

\footnotetext{
${ }^{1}$ Historiadoras costurricenses.
} 
Para seleccionar las persona a entrevistar se tomó en cuenta -hasta donde fue posible- a pequeños, medianos y grandes productores, lo mismo que a los que ya no poseen tierra. Al hablar con los y las informantes sobre su experiencia vivencial y agrícola, sus perspectivas enriquecen el conocimiento histórico de la actividad cafetalera y del cantón, en tanto reflejan un universo de similitudes y diferencias que no se pueden dejar de lado, en una síntesis de la historia patria. De allí la riqueza metodológica que brinda la historia oral, en tanto nos posibilita conocer el pasado de sectores sociales invisibilizados en las fuentes históricas tradiciones y olvidados en la "vallecentralidad" de algunas interpretaciones.

Temáticamente, este trabajo presenta el desarrollo del cultivo cafetalero en Tilarán, a partir del proceso colonizador iniciado en la última década del siglo XIX, donde la mayoría de las familias migrantes procedían del Valle Central, concretamente de pueblos alajuelenses y heredianos, que ya para 1890 tenían bastante cimentada una cultura cafetalera. Esta situación explica el porqué al llegar a los nuevos lugares a donde migraban pretendieron, en primera instancia, repetir los cultivos y sistemas de producción que habían aprendido desde niños en sus lugares de procedencia. De esta forma, después de los desmontes y socolas, cultivaron primero granos básicos de subsistencia, algunos cereales, pastos y más adelante, como símbolo de pertenencia y de lo que hablan dejado atrás, el grano de oro.

En las siguientes líneas veremos la historia del café en Tilarán, incluyendo las etapas críticas que llevaron el descenso en la producción. El estudio se dividirá en dos apartados. El primero que va de 1900 a 1950, se referirá a las particularidades del cultivo por los primeros colonos, en donde se harán algunas menciones al beneficiado, comer- 
cialización y descenso de la actividad. El segundo tratará del impacto del proyecto hidroeléctrico de Arenal, en cuanto a nuevas opciones para el uso del suelo. Con respecto al café se verá la introducción de nuevas variedades con la aplicación del paquete tecnológico y sus resultados para el caso de Tilarán. También el beneficiado, la creación de una cooperativa de productores, la comercialización, la crisis de los años 90 y los nuevos retos a raíz de esa crisis.

\section{El café en el proceso de colonización agrícola de Tilarán}

Las tierras altas del Guanacaste, concretamente Tilarán y Abangares, se vieron inmersas a finales del siglo XIX en un gran proyecto capitalista que pretendía incorporar esas tierras al resto del país mediante la construcción de un ferrocarril ${ }^{2}$. Paralelo a la idea de esta vía y siempre dentro del citado proyecto, se constituyó una sociedad, la Santa Rosa Coffee States, cuyo objetivo era destinar 1.000 hectáreas al cultivo del café. Para ello se utilizó la Hacienda Quebrada Azul, ubicada en lo que es actualmente Tilarán, la superficie sembrada alcanzó apenas a unas 60 hectáreas y ya para 1898 , se menciona que de sus 1.000 hectáreas de extensión, 45 estaban cultivadas de café de cuatro años, obviamente la empresa fracasó ${ }^{3}$. Así fue como las haciendas mayores de la región en ese entonces, Quebrada Azul, Lombardía y La Laguna, iniciaron la siembra del grano desde finales del siglo anterior. Referencia a ello se encuentra en algunos relatos de viajeros quienes indicaban para 1896,

\footnotetext{
"Carolyn Hall. Carolyn Hall. El café y el desarrollo hist6rico-geográfico de Costa Rica. (Costa Rica, editorial Costa Rica y Universidad Nacional, 1976), p. 129.

"Brunilda Hilje. "Colonización agrícola de Tilarán 1880-1950". (Heredia, UNA, Tesis de Licenciatura en Historia, 1987), p. 126

${ }^{4}$ Henri Pittier. ."Con el Obispo Thiel en Guanacaste, 1896". en Viajeros por Guanacaste. Recopilación Dr. Carlos Meléndez (Costa Rica, Ministerio de Cultura, Juventud y Deportes, 1974), p. 311.
} 
la existencia del cultivo en dos fincas Santa Rosa, nombre con que se conoció a la Hacienda Quebrada Azul, y La Flor de América, esta última, con menor cantidad de café sembrado, era más eficiente en cuanto a productividad que Santa Rosa $^{4}$.

Sin embargo, dado el predominio de la gran propiedad al inicio del proceso colonizador, el café ocupó un porcentaje pequeño del total cultivado de la tierra, considerando que eran haciendas con una cabida mayor a las 1.000 hectáreas. Esto marca una diferencia con el Valle Central, donde para la misma época, la propiedad de la tierra se caracterizaba por la división de fundos cada vez más pequeños y la casi carencia de tierra baldía ${ }^{5}$.

De esta manera, la abundancia de tierra disponible en Tilarán, posibilitaba a las familias migrantes obtener terrenos ya fuese por compraventa, denuncio o acarrilamiento, de acuerdo a sus posibilidades económicas. De esto Iban a depender también las opciones de cultivo. Algunos de los primeros migrantes del Valle Central a Tilarán, compraron fincas "ya hechas", donde habían siembras de café 6 . A esto nos hacen referencia los nietos de los primeros migrantes, de sus testimonios se evidencia que cultivaron café, cana de azúcar y granos básicos, aunque había mayor tendencia a la ganadería.

En el distrito de Líbano que nació al calor de la explotación minera, el café se sembró en algunas pequeñas parcelas? ${ }^{7}$ Uno de los entrevistados, que llegó ahí en 1919, siendo niño, no recuerda que hubiese café,

\footnotetext{
"Varios autores, entre ellos: Yolanda Barres. "Las transacciones inmobiliarias en el Valle Central y la expansión cafetalera en Costa Rica (1800-1850") (San José, U.C.R., Tesis Licenciatura, Escuela de Ciencias del Hombre, 1975). Gerhard Sandner. La colonizacion agrícola de Costa Rica (Costa Rica, Instituto Geográfico de Costa Rica, Tomo 1, 1962). 6 Archivo Nacional de Costa Rica, en adelante ANCR, Alcaldía Unica de Cañas, No. 589, 29-6-1909.
}

${ }^{7}$ ANCR. Varias compraventas. Años 1914-1917, fs. 22-23-27v-29, 11-5-1917. 
"Aquí, aquí, en el propio Líbano, no. Es que, para el café era bueno el Cerro, Cerro san José, ahi sí había café (...) una finca grande que tenía bastante café, (...) fue primero de un macho que se llamaba mister Hanckel, ese era el que tenía café, después él salió y no recuerdo a quién vendieron eso" 8 .

Otra finca que sembró café fue La Argentina, de don Fausto Calderón. De acuerdo al Censo Cafetalero de 1935, era el mayor productor de la región, con un área cultivada de 50 hectáreas; además, tenía su propio beneficio. Según las compraventas de terrenos entre 1900 y 1929, la mayoría de los migrantes a Tilarán cultivaron café. Ello se percibe de las transacciones inmobiliarias de este período aunque no se especifique la extensión exacta. De esos mismos datos se puede constatar que aunque el café fue una actividad significativa, estuvo siempre muy por debajo de la ganadería. Por ejemplo, en 1900 la finca La Conchita, situada en terrenos que habían sido municipales, de una extensión de 100 hectáreas, dedicaba 20 manzanas a café, 20 manzanas a potrero cercado, 2 manzanas a caña de azúcar; el resto era de tacotales y montaña. Al año siguiente, en otra propiedad de 451/2 hectáreas, hablan 6 hectáreas de café, 2 hectáreas de potrero, 1 hectárea de caña de azúcar y el resto de tacotales y montes. Pero ya en 1910 , en esos mismos terrenos de origen municipal, una finca de 300 hectáreas, tenía 150 hectáreas de potrero, 14 hectáreas de caña de azúcar y 3 hectáreas de café. En el caso de la finca La Conchita, en 1900 , quizá la cantidad sembrada fuera el remanente de las siembras auspiciadas a partir de 1894 y que tuvieron un descenso paulatino.

\footnotetext{
${ }^{8}$ Entrevista al señor Manuel Cabezas Chavez, el día 11 de agosto de 1994 en Líbano de Tilarán.
} 
En el año 1910, los vecinos de Tilarán al mencionar el aumento de población, manifestaron que ya para esa fecha existía el cuadrante y una extensión de 2000 hectáreas de cultivos estables. El café se sembraba en 35 hectáreas, el resto era de cana de azúcar, plátanos, potreros y terrenos dedicados a la siembra de granos ${ }^{9}$. Según las compraventas entre 1901 y 1916 , para el caso de seis fincas que especifican la extensión de cada cultivo, de un total de 484 hectáreas, habla 26 hectáreas sembradas de café, la mitad en mal estado, en contraposición a 167 hectáreas de potrero y 230 hectáreas de tacotal y monte. En el periodo 1917-1932, el dato de 35 fincas con una extensión de 1555 hectáreas, arrojaba 14.58 hectáreas de café y 355.77 hectáreas de pastos.

Tal era el panorama agrícola de Tilarán, a pesar de que en 1922 hubo un proyecto, luego convertido en ley, para poblar con caficultores las tierras altas del Guanacaste; y que agricultores de Tilarán aprovecharon los préstamos ofrecidos Por el Banco Internacional en la década de 1920 para expandir el cultivo del grano. Entre 1930 y 1932 , el dato de 47 fincas en precario es de 33.92 hectáreas de café en contraposición de 1.032.51 hectáreas de repastos. De esta forma, descrito a grandes rasgos el uso dado al suelo en el proceso colonizador de Tilarán, abordaremos las características del cultivo y comercialización del café en contraposición de 1.032 .51 hectáreas de repastos

\section{Las variedades de Café y las prácticas agrícolas utilizadas}

Al evocar su pasado cafetalero nuestros informantes recalcan que el café que se sembraba era el conocido comúnmente arábigo o café criollo. En palabras de uno de ellos,

\footnotetext{
${ }^{9}$ En la investigación artiba citada de Carolyn Hall se menciona, que ya para 1916 en la colonia de Tilarán se hablan sembrado 150 hectáreas más de café; no obstante que la altitud no era la más óptima.
} 
"si, porque antes era un café criollo verdá, que le decíamos nosotros, se hacían ranchos grandes y las matas así..."10

Este café de porte alto, algunas personas lo llamaron indistintamente árabe, café criollo o barbón, lo que viene a destacar la introducción de otra variedad que en forma paralela se fue desarrollando junto al criollo.

Como ya se mencionó, las grandes haciendas de Tilarán Iniciaron el cultivo del café desde finales del siglo anterior, al decaer las siembras por el abandono de algunas de esas tierras, se formó una nueva vegetación, quedando algunas semillas o matas de café dispersas. Un vecino de Los Ángeles, nos relata un proceso particular.

"la gente vieja que habla sembrado el café antes, eh, los mismos pájaros hacían los regueros en las montañas a las orillas, entonces se creaban las matas, entonces el café que se sembraba lo agarraba uno y lo hacia jalao, lo que antes se llamaba sembrar el café en chilillo y entonces era el cafetal el que se arrancaba de la montaña" ${ }^{\prime \prime}$.

Otros hicieron sus propios almácigos utilizando los mismos métodos del Valle Central de Costa Rica, estos nos hablan sobre el período de siembra y el sistema utilizado. Los meses para hacer el almácigo eran:

"de mayo en adelante, donde ya llueve duro, que la semilla la pone uno a nacer con tiempo. Uno pone el montón de café y lo está humedeciendo y lo tapa con hoja de banano

\footnotetext{
${ }^{10}$ Entrevista realizada al señor Claudio Núñez González, el día 20 de abril de 1994, en Tierras Morenas, Tilarán.

"Entrevista realizada al señor Ivar Meléndez López, el 13 de junio de 1995, en Los Ángeles de Tilarán.
} 
y le está rociando agua, es cuando está con la patota afuera, entonces uno lo trasplanta, se hace el hoyo, el huequiIlo ahí y lo va trasplantando a una distancia así más o menos, para después sacarlo en adobe (...) hay gente que lo hace escobiado también" 12 .

Para trasportarlo al lugar final de siembra, lo envolvían en cáscara de banano. Las herramientas utilizadas para hacer los semilleros eran palas y azadones, con ellos se limpiaba y preparaba el terreno para la siembra de las semillas.

Una vez trasplantado el café, se le ponla sombra, práctica controversial, pero que en el pasado fue de uso general.

Los cultivadores de café en Tilarán repitieron en su nuevo asentamiento las prácticas agrícolas ya conocidas por ellos. Una de estas fue la sombra, condicionada por los factores climáticos o la particularidad de las tierras colonizadas, utilizando particularmente jocote, plátano, guineo negro y guaba. Como en el cantón habla diferencias climáticas de uno a otro distrito, los sistemas se desarrollaron con algunas diferencias. En el caso de Tierras Morenas, el uso excesivo de la sombra fue contraproducente, las lluvias constantes hacían descender las temperaturas y esto dañaba los cafetos. Otros emplearon la sombra natural de la montaña, que poseía los árboles de níspero, cedro, laurel, ceibo y otras especies nativas.

Toda esta mención a la riqueza del bosque primitivo, nos impulsó a inquirir sobre los tapavientos como protección al café. Uno de nuestros entrevistados explica que:

'como casi todos los derredores de los cafetales, diay, todos eran montaña, no se necesitaba de tapavientos. Ya últimamente, ya se fue haciendo, eh, se fue apropiando la

\footnotetext{
${ }^{12}$ Entrevista al señor José Antonio Palma, el 20 de abril de 1994, en Tierras Morenas de Tilarăn.
} 
montaña, si se le dejaba, ya lo que se llamaba antes una burra de monte, le decía uno, a los, a los tapavientos, (...) árbol natural, sí, sí. Más bien a la gente, eh, le gustaba mucho sembrar palos de aguacate, naranjas, limones y todo eso se le iba metiendo también para ir quitando la otra resto de montaña"15.

Una vez que los cafetos crecían y daban fruto no requerían de mayores cuidados. Lo usual eran las chapias para mantenerlos libres de maleza. También se usaron las paleas para aporcar las plantaciones, impidiendo con ello el lavado de las raíces por el exceso de lluvias.

Una de las particularidades del cultivo del café en el pasado fue la escasa y a veces inexistente aplicación de abono en las plantaciones. Tilarán no fue la excepción porque además de que esa práctica no era común, la feracidad de sus suelos fue notoria en los inicios del proceso colonizador. Un informante enfatiza que,

"era nada más que limpiar, paliar y ahora viven echándole abono y todo eso, pero antes no, antes nada de eso hacian" 14.

Los entrevistados fueron coincidentes en este aspecto. En cuanto a los cuidados de los cafetos otra práctica que se puede señalar es el de podar. Dado que en Tilarán se presenta un período mayor de pluviosidad que en el Valle Central, los cultivadores de cafë debieron enfrentarse al mayor desarrollo de los arbustos y a la necesidad de podar. Nuestros informantes recuerdan que cuando el café crecía mucho se le quitaban las ramas más altas para que nacieran

\footnotetext{
13 Entrevista al señor Ivar Meléndez.

${ }^{14}$ Entrevista al señor Sergio Ruiz Alfaro, el 21 de abril de 1994, en Tierras Morenas de Tilarán.
} 
nuevos hijos. Esta tarea se hacia con machete o con un pequeño serrucho.

Otra de las prácticas subsiguientes a la poda es la deshija. Esta consiste en eliminar algunos hijos nuevos de los cafetos. El productor, yen algunos casos un peón conocedor, seleccionaba los hijos que se podían suprimir para garantizarle al resto de la planta el crecimiento y fuerza que asegurara una mejor cosecha. Por lo general se dejaban dos o tres hijos, esta labor se hacia manualmente.

Una práctica similar al Valle Central fue la repoblación o la resiembra. Los cafetos dañados fueron sustituidos en forma individual, nunca eliminando calles enteras.

Al igual que en el Valle Central, las plantas de café en Tilarán se vieron atacadas por plagas y enfermedades. A veces, su desconocimiento hizo que no fuesen combatidas a tiempo. Los entrevistados recuerdan algunas de ellas como el ojo de gallo, cuya particularidad es que el cafetal esta todo llenito de ojillos, la maya que consiste en granos secos no aprovechables, la gotera en que debido al exceso de lluvia y a la presencia de árboles cercanos a los cafetales, las hojas de las plantas se toman amarillas y se caen. Más recientemente, hubo problemas por la aparición de la roya. Otro enemigo de los productores fueron las taltuzas, pequeño roedor que atacaba la raíz de los cafetos y llevaba por ende a la extinción de las plantas.

Además de esto, también quisimos indagar si existían diferencias con respecto al Valle Central, en cuanto a la distancia de siembra de las matas, productividad y duración de los cafetales. Por ejemplo, en Tierras Morenas se nos indica que,

\footnotetext{
"este siembra de dos varas a dos y media varas, eso depende del gusto del dueño, vea, y el borbón a tres varas porque desarrolla muchísimo" 15
}

\footnotetext{
${ }^{15}$ Entrevista al señor José A. Palma.
} 
En cuanto a los rendimientos en la producción de café se destaca la feracidad de los terrenos, treinta o cuarenta anos atrás.

"Pues si, (...) una manzana de café (en 1945) se venia ahi tal vez con cuarenta. Cincuenta fanegas de café, sí, eran buenísimas los cafetales"16

En relación con la vida productiva de las variedades se nos dice que,

"puede durarle veinticinco años una mata de café criollo y otra ventaja que tenía, que la granea salía del café grueso grano, vea salía del café el café grueso y la repela estaba buen, buen grano también, salía parejo al grano...."17

Otro caficultor mencionó que el café borbón duraba en producción consecutiva hasta cuarenta años, como el primer café que se sembró con fines comerciales a mediados del siglo XIX en el valle central.

\section{La recolecta, procesamiento y comercialización del café}

Hubo coincidencia entre los entrevistados, al señalar que la recolección del café en el pasado no generaba problemas porque la mano de obra era abundante.

Generalmente de esta tarea se encargaban las mujeres y los niños. Una de ellas, nos relata una forma particular de recolecta.

"mire se pone un manteado, con en cada esquina del manteado se pone una estaca, se pone, se extiende y

\footnotetext{
${ }^{16}$ Entrevista al señor Iván Meléndez.

"Entrevista al șeñor Juan R. Alvarado Herrera, el 21 de abril de 1994, en Tierras Morenas en Tilarán
} 
clavan las estacas y alli se acumulan un gancho que jala las ramas de café y se amarran las matas de café y ahí está uno, ra, ra, ra, ra..."18

Existe una diferencia que cabe destacar con respecto al valle central y es el procesamiento del grano una vez recogido. Por lo general, en Tilarán las parcelas sembradas de café fueron pequeñas a lo sumo tres manzanas. Así, en muchos casos el grano no se llevaba a los beneficios sino tenía otra forma de comercialización.

Una vez recolectado el fruto, lo ponían a secar al sol en sus propias casas. Luego ya seco al grano, lo descaraban utilizando un pilón, después lo pasaban por una maquina especial para limpiarlo totalmente.

Verificado este proceso se comercializaba, vendiéndolo a comerciantes locales o foráneos que actuaban como intermediarios. Estos por lo general procedían de la provincia de Alajuela.

Mas adelante, con la creación de beneficios cercanos lo usual fue entregar el café en fruta, lo que elimino la vieja práctica manual.

En cuanto al transporte de ese café ya fuera para beneficio o bien para la venta semiprocesado todos coinciden en que se hacía en carretera o a caballo.

Uno de ellos resume la evolución del transporte a través de esos años,

"... al principio lo sacaban a caballo, después con bueyes, después en camión." 19

\footnotetext{
${ }^{18}$ Entrevista a la señora Mercedes Chaves Chaves el 30 de mayo de 1994, en Los Ángeles de Tilarán

${ }^{19}$ Entrevista al señor Rafael Murillo Murillo, el 22 de junio de 1994, en Tronadora de Tilarán.
} 


\section{Decadencia del cultivo en su primera etapa}

Si bien en Tilarán el café se sembró con mayor intensidad entre 1920 y 1930, la disminución yen algunos casos la desaparición de los cafetales se debe a diversos factores. Algunos de ellos fueron la humedad del aire, los fuertes vientos y la escoria volcánica, que llevaron a los propietarios de fincas tanto grandes como pequeñas al cambio hacia la ganadería. Un vecino de Los Ángeles, nos dice,

"En esa finca habla. Pues no mucho, pero habla como unas cinco manzanas de café, pero en ese tiempo era el café que se sembraba, a como se sembraba antes, no cafetales ya modernos de ahora, entonces ya eran cajetales viejísimos ya, eran cafetales de cuarenta, cincuenta aftos de sembrado, entonces se fueron perriJen doy ya prácticamente aquí el café, no sirve el café. ${ }^{20}$

En Líbano, en el Cerro San José,

"Ya ahora destruyeron todos los cafetales. (...) No queda nada. Solo pasto (...) Sí era muy bonito ahi, muy bonito porque habia montaña (...) En ese tiempo, esos cafetales estaban llenos de madera. Mucho cedro y níspero tenía mucho también. (...) Todo eso lo botaron, eso era lo que le daba vida a este lugar, porque en tiempo de cogida de café, todo mundo iba para allá a coger café, se terminó" 21

Cuando el ICE inició los estudios para la creación del embalse de Arenal y la reubicación de las poblaciones afectadas por el proyecto, se habló de que la transformación del

\footnotetext{
${ }^{20}$ Entrevista al señor Ivar Meléndez...

${ }^{21}$ Entrevista al señor Manuel Cabezas..
} 
suelo y su cambio de agrícola a ganadero se había dado antes de 1960.

"Como indicadores del pasado, se encontraron algunos viejos cafetales con enormes árboles de sombra en las haciendas grandes $y$, casi como reducto de los campesinos cafetaleros de la Meseta Central, unas concentraciones de fincas de pequeño y mediano tamaño. Con cultivos de café, cada. Frutales y granos básicos... (en contraposición a)... un mar de zacate interrumpido en tramos por franjas de bosques bordeando las quebradas y nacimientos de agua y por pequeños lotes de bosque degradado, tacotal y charral esparcidos en las lomas..."22

Así pues, la reubicación de dos poblaciones completas a raíz de la construcción del proyecto hidroeléctrico Arenal, conllevó a consideraciones económico-sociales en tomo a qué actividades productivas se iban a desarrollar en ellas, qué cultivos se iban a promover, qué facilidades crediticias ofrecerán para ello el Estado y las instituciones privadas, qué Innovaciones tecnológicas estarían al alcance de los productores, referente a semillas mejoradas, sistemas de producción, transporte y procesamiento de los productos, entre otros.

\section{El café en la Cuenca del Arenal}

A continuación se explica la experiencia que representó para los productores de Nuevo Arenal y Nueva Tronadora el cultivo del café, como actividad promovida por el Estado y sus instituciones autónomas, para insertar a estos pueblos al mercado y evitar la migración al Valle Central u

22 Joseph Tossi. Estudio eco/6gico integral de las zonas de afectacion del proyecto Arenal. (Costa Rica, Centro Científico Tropical, 1980) p. 1-125. 
otras zonas. Inicialmente, la actividad cafetalera no fue la única promovida, la ganadería de leche, macadamia y algunas legumbres fueron también sometidos a estudio para valorar la posibilidad de estimularlas en la zona, pero fue el café en su calidad de cultivo perenne y de incorporador de mano de obra familiar, de actividad conocida tradicionalmente por los campesinos "meseteños" (antepasados directos de quienes migraron y colonizaron Tilarán) y de avances tecnológicos en cuanto a su cultivo y procesamiento, el que logró materializar en la mayoría de las Instituciones (ICE - Sistema Bancario Nacional - beneficios privados - MAG) los esfuerzos requeridos para desarrollarse ${ }^{23}$.

\section{Métodos de cultivo}

La siembra del café estuvo asociada a las variedades caturra y catuaí, café deporte bajo. Los productores contaron con, un paquete tecnológico bien definido en lo concerniente a distancia de siembra, semilla mejorada, abono, control de plagas y también en lo que al crédito dirigido se refería.

Al nacer la Cooperativa de caficultores, era ella la que distribuía la semilla y quien además, vendía los almácigos en la mayoría de las ocasiones, aunque algunos productores, los hacían ellos mismos. Pese a que esta práctica, heredada de los antiguos sistemas de producción de café propios de la Meseta Central, se mantuvo en algunos productores de Arenal, los avances tecnológicos patentizaron que las semillas mejoradas aseguraban una mejor cosecha y un rendimiento más alto, por ello varios productores, solo sembraron el café que en almácigo, era vendido por la Cooperativa como vocera de estos cambios.

\footnotetext{
${ }^{23}$ Véase al respecto el trabajo de las autoras acerca de este tema, en la Revista de Historia (Costa Rica, UNA-UCR, No. 33,1998).
} 
Este café se debla fumigar a partir de que la planta germinaba, cada 15 días se aplicaba el atomizo para que estuviera libre de malezas, luego de al se transplantaba al cafetal, mediante el sistema conocido como. "espullonado".

Para la siembra, los técnicos del Convenio MAG.ICE señalaron las medidas necesarias para lograr el mayor rendimiento posible, de ahí que fueran estrictos en lo que a semilla, siembra y trasplante se refiere puesto que esta fase era primordial para la configuración del cafetal y las posteriores etapas del sistema productivo.

Por lo general, la distancia de siembra era de dos metros por uno, calculando aproximadamente cinco mil quinientas plantas por hectárea. Pese ahí bien definido del discurso, estas disposiciones técnicas presentaron problemas en Tilarán, en especial por la lluvia y las condiciones del suelo. Un productor de café resume las manifestaciones de los informantes,

". . las recomendaciones que trajeron los ingenieros eran muy estrictas en cuanto al sistema de siembra, las distancias, porque ellos, si uno no acataba la orden de ellos entonces le suspendían el crédito y como era un crédito di rígido... entonces uno se vela obligado a acatar las recomendaciones del ingeniero. Díay imagínese que aqui nos recomendaron dos metros por uno, era una verdadera tupición, era fatalidad, había veces que uno no podía cruzar entre calles y ahí el bandoleaje se cruzaba uno con el otro y ahi cuando el café se alzaba un poco para bajarlo, díay a qué ya estaba uno pegando en la otra planta, no habla lugar para donde bajar al café, viera que cosa más tremenda. no dejaba de ser problemático ese sistema de siembra". ${ }^{24}$

\footnotetext{
${ }^{24}$ Entrevisca realizada al señor Joaquín Pérez ell 8 de octubre de 1994 en Arenal, Tilarán.
} 
Las primeras cosechas se obtuvieron a los dos anos de transplantado el cafetal, en especial por la lluvia, los suelos muy fértiles y por ser las primeras siembras que brotaban de ella, además de la asistencia técnica y el crédito que recibían los productores, el promedio obtenido fue de aproximadamente 50 fanegas por

El problema que encontraron los productores con el café de porte bajo (caturra, catuaí) fue que la vida productiva de la mata era más corta que las del café de porte alto, donde la vida del cafetal podía alcanzar los 40 anos.

Los productores de Tilarán conocían las condiciones en que trabajaban, tanto climáticas, como físicas y crediticias. Así que concientes de que ellos eran quienes debían cancelar los créditos otorgados y no quienes técnicamente aconsejaban las medidas, empezaron a adaptar el paquete tecnológico ofrecido a sus necesidades, modificando en este sentido, las disposiciones técnicas de los agrónomos. Fue así como implementaron un sistema de poda de tres tipos: "rock and roll" a un metro de altura del suelo, otra de cuarenta centímetros y otra de treinta. Incluso acostumbraban podar una calle y dejar dos en producción, de manera que al ano siguiente se pudiese cortar una, otra estarla en crecimiento y dos se encontrarían en producción.

Recordemos que las condiciones climáticas no hacían necesaria una sombra muy tupida pues la lluvia constante refresca el ambiente, aunque los abrigos o tapavientos si son imprescindibles. Algunos de los informantes coincidieron en que la sombra no es recomendable en tanto el café disminuye la producción por el exceso de lluvia, además la maduración no es pareja alargando el periodo de recolección a seis meses.

En lo que si coincidieron fue en la siembra y obtención de abrigos para la cosecha, en ellos sobresalen el colpachí, y la cana india, aunque si las circunstancias lo permitían se 
aprovechaban las montanas o los pocos tapavientos naturales que se encuentran, para aminorar la inclemencia de los vientos.

Otra actividad de vital importancia en estos cafetal fue la deshija en tanto aseguraba que la producción fuera pareja y que la planta se mantuviera vigorosa. En Nuevo Arenal se practicaron por lo general dos deshijas de forma manual, aunque si la posición de la rama lo ameritaba se cortaba con un cuchillo o serrucho. Cuando una planta se enfermaba o ya habla dado suficiente producción, se procedía a eliminarla yen su lugar se siembra otra, este fue el mecanismo de resiembra más usado en la zona, así no hay una planificación en cuanto a la edad promedio del café, productividad y renovación del cultivo.

Por las condiciones topográficas de Tilarán, el prevenir la erosión es primordial para el caficultor, pues de lo contrario los terrenos se lavan fácilmente. Un informante de Nuevo Arenal dijo al respecto:

[para prevenir la erosión] "hacíamos curvas de nivel y mantengamos siempre las curvas limpias, entonces las lluvias, las aguas corrían mancitas verdá, salían y no habla mucho lavadero" 25 .

Otro problema con el que lucharon los productores consistió en la serie de plagas y enfermedades que atacan el café, sobre todo la roya, el ojo de gallo y la chasparria en la época lluviosa y la cochinilla en la estación seca.

Sin embargo, con la asistencia oportuna de los técnicos e ingenieros se obtuvieron buenas cosechas a principios de la actividad en las zonas reubicadas, sobre todo antes de empezar la poda por calles, cuando todo el cafetal estuvo

${ }^{25}$ Entrevista al señor Francisco Vargas, el 17 de octubre de 1994 en Nuevo Arenal, Tilarán. 
en producción. Un problema al que debieron enfrentarse fue que no existía una cultura de recolectores de café como en la Meseta Central. Además tuvieron que competir por la mano de obra con los sectores del turismo y de la construcción, que brindaban trabajo bien remunerado, con garantías sociales y con mayor prestigio social que las labores vinculadas al cultivo de la tierra. Un vecino nos cuenta que:

\begin{abstract}
"no hay gente para trabajar [en café] la m ay aria se ha dedicado a construir, porque se han metido mucho los extranjeros, nosotros llamamos gringos, verdad, alemanes, todo lo que es extranjero y entonces hay mucha construcción, pagan muy bien y entonces la gente se ha dedicado a trabajar en eso. Hay algunos hoteles y entonces las mujeres que cogian café ahora están ganando buen sueldo en los hoteles, en las casas de los gringos y así por el estilo"26.
\end{abstract}

La difícil situación por acopiar la mano de obra necesaria para recolectar café, sobre todo si se tiene en cuenta la disparidad en la maduración, se agravó con el problema de transporte, beneficiado y comercialización del producto. Toda esta problemática llevó a los agricultores a buscar una manera más efectiva de resolverlos institucionalmente y fue así (, como luego de varias reuniones entre ellos se llegó a materializar la creación de una Cooperativa que luego de los problemas Iniciales pudo ofrecer un buen servicio, inclusive se mantuvo como único recibidor y beneficiador de - café en el cantón (aunque siempre tuvo pérdidas).

Los productores vendían al café en cereza a la Cooperativa para que fuera ella la que lo procesara, ello conllevó a plantearse el problema del transporte al recibidor y luego el pago del costo del flete hasta el beneficio, el cual era

\footnotetext{
${ }^{26}$ Entrevista al señor Alturo Barrientos Calderón, el 23 de junio de 1994, en Guadalajara, Tilarín.
} 
descontado del adelanto por la cosecha. No obstante, una minor(a de los productores pequeños procesaba el fruto manualmente y lo vendía (a en pergamino a comerciantes de la Meseta Central.

Uno de nuestros informantes nos cuenta como procesan el grano para su comercialización

"... Usted lo seca sin hacerle ningún trabajo ese se llama bellota. Y si usted lo chanca, en un chancador y lo lava y lo seca ese se llama pergamino. Asílo vendo yo, lavado y de todo, ahi no hay fermento de nada"27.

Este tipo de productores, ha sentido cómo los costos de producción han subido puesto que ya en estos tiempos se deben cancelar todos los servicios (técnicos, de transporte, de beneficiado) en dinero, pues han dejado de ser utilizadas predominantemente, las carretas y la mano de obra familiar ya que sus hijos optan por estudiar o trabajar en otros sectores y no en las unidades productivas de sus padres. Uno de los entrevistados nos dijo que

"... al productor le dan en estos momentos cuatro mil quinientos pesos por fanegay lo que le quedan son treinta y cinco pesos por fanega, por fanega al productor, no le alcanza ni pa'comer (...) pagando por recolección de café ciento setenta y cinco colones por cajuela, recolección quince colones de transporte, le da tanta y más la empresa le cobra del recibidor al beneficio no sé cuánto... y de ahí más el diez por ciento que le quitan, no le queda nada, en estos momentos no le queda nada al productor 28 .

\footnotetext{
${ }^{27}$ Entrevista al señor José Antonio Palma Espinoza, el 20 de abril de 1994, en Tierras Morenas, Tilarán.

${ }^{28}$ Entrevista al señor Elio Rojas, el 17 de octubre de 1994 en Dos Bocas de Arenal, Tilarán.
} 
Esta situación se agravó al inicio de los años 90"s cuando las crisis de los precios bajos afecto al caficultor nacional y conlleva a la pérdida de cafetales, venta de tierras y la diversificación agrícola y cambio radical del uso del suelo hacia la urbanización y servicios (como el turismo).

El abandono de los cafetales fue una opción drástica utilizada por los productores que no dependían únicamente de la explotación de ese producto, o que por serlo no pudieron enfrentar la crisis en el agro y se vincularon se vincularon como trabajadores de otros sectores. Un relato dice,

"los cafetales se encharralaron y eso, y ahí están ahorita, porque yo me he retirado a trabajar en el campo y no me quedo dinero para mantener la finca y entonces ahora estoy vendiéndola, tal vez ahí voy a poder recuperar un poco, por que ahora venden muy bien las tierras aquí (silencio)."29

La opción con que ha sobresalido un poco el pequeño productor es con el cultivo de chile, tomate, chayotes y tubérculos, así como con la combinación café y la macadamia, ya que como cultivos intercalados dan buenos rendimientos. Los productores más pobres cultivan hortalizas que requieren menos inversión y producen más rápido que el café y la macadamia. Incluso en la zona se desarrollan proyectos de pequeñas Industrias para procesarlas en encurtido, o bien las comercializan en las ferias del agricultor.

Como vemos el cultivo del café ante los bajos precios y el problema de acceso a mano de obra ha originado que se haya modificado el sistema de producción o de combine con otros cultivos de más rápida cosecha y de menos costo de inversión. Así el cultivo de café subsiste pero en agonía,

${ }^{79}$ Entrevista al señor Arturo Barrientos... 
sobre todo cuando las condiciones de producción no aseguran un producto de calidad. 